\title{
PENGARUH PENAMBAHAN SODIUM HIPOKLORIT DALAM ANALISA AMONIA AIR SECARA FENAT
}

\author{
Haspiadi, Kurniawaty dan Fitriani \\ Balai Riset dan Standardisasi Industri Samarinda
}

\begin{abstract}
The research has been conducted to study the effect of the addition sodium hypochlorite on the ammonia testing of water and waste water. This research was investigated the effect of excess of sodium hypochlorite that added in to the sample has high turbidity. Sodium hypochlorite solution to reduce turbidity was used at various volume: $25 \mathrm{~mL}, 30 \mathrm{~mL}, 35 \mathrm{~mL}, 40 \mathrm{~mL}$, $45 \mathrm{~mL}, 50 \mathrm{~mL}, 55 \mathrm{~mL}, 60 \mathrm{~mL}$. The analysis method according to SNI 066989.30-2005, Methode of Amonia Testing with Spektrofotometer in water and waste water.The result of the experiment indicate that sodium hypochlorite was added more than arranged in SNI 06-6989.30-2005 can effect to the result of actual ammonia contain in the water sample. The maximum of sodium hypochlorite recommended to used in the sample high turbidity is $40 \mathrm{~mL}$ in $100 \mathrm{~mL}$ alkalin citrate solution.
\end{abstract}

Keywords : ammonia, sodium hypochlorite, turbidity, water and waste water

\section{PENDAHULUAN}

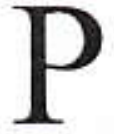
engujian amonia dalam air dan air limbah dapat dilakukan dengan beberapa metode. uji seperti SNI (Standar Nasional Indonesia), Standard Methods, JIS (Japan International Standardisation) dan metode uji lainnya. Setiap metode uji tersebut memiliki keunggulan dan kelemahan baik ditinjau dari tingkat kesulitan penerapan dilapangan maupun ketersediaan jenis peralatan dan bahan kimia yang dipersyaratkan untuk digunakan.

Salah satu metode pengujian yang ditetapkan dalam Standar Nasional Indonesia adalah metode uji amonia dalam air dan air limbah. Metode uji ini telah berkembang sesuai kondisi dilapangan dan telah mengalami revisi dari yang sebelumnya adalah SNI 191655-1989 tentang Metode Pengujian Kadar Amonium dalam Air dan Air Buangan dengan alat Spektrofoto meter secara Nesler. Kemudian direvisi menjadi SNI 06-6989.30-2005 tentang
Air dan Air Limbah - Bagian 30: Cara Uji Kadar Amonia dengan Spektrofotometer secara Fenat.

Latar belakang direvisinya Metode Uji Amonia sesuai SNI 19-1655-1989 secara nessler menjadi SNI 066989.30-2005 secara fenat, karena dalam penerapannya masih menggunakan bahan-bahan kimia yang sifatnya berbahaya atau toksit seperti merkuri iodida $\left(\mathrm{HgI}_{2}\right)$, sehingga tidak aman bagi lingkungan.

Namun dalam penerapan di lapangan Metode Uji Amonia sesuai SNI 06-6989.30-2005 secara Fenat, ditemukan permasalahan sulitnya menerapkan untuk sample yang keruh. dimana dengan metode Nessler dapat dieleminir dengan cara destilasi. Namun untuk metode fenat tanpa dilakukan destilasi dan hanya penambahan sodium hipoklorit $(\mathrm{NaOCl})$ dengan volume yang telah ditetapkan dalam standar uji tersebut yang berlaku untuk semua jenis sampel. Sedangkan tingkat 
kekeruh an dan warna sampel yang diujikan berbeda-beda sesuai dengan sumbernya.

Penggunaan sodium hipoklorit dalam analisa amonia pada suasana basa $(\mathrm{pH}=8-11,5)$ bereaksi dengan amoniak membentuk senyawa monokloramin (kiunon kloramin). Senyawa monokloramin yang terbentuk ekivalen dengan banyaknya amonia yang terdapat dalam contoh air dengan indikator pembentukan warna biru. Namun kenyataan dalam pengujian untuk sampel yang keruh warna biru yang terbentuk akan dipengaruhi oleh keadaan sampel dengan kekeruhan yang tinggi.

Tingkat kekeruhan sampel dapat diatasi dengan penambahan sodium hipoklorit dalam jumlah yang lebih besar dari yang ditetapkan dalam prosedur uji. tetapi sebagaimana reaksi monokloramin yang terbentuk antara amonia dan sodium hipoklorit ekivalen dengan banyaknya amonia dalam sampel uji. Sehingga perlu ada batasan jumlah sodium hipoklorit yang dapat digunakan.

Oleh karena itu untuk mengetahui bagaimana pengaruh penambahan sodium hipoklorit ( $\mathrm{NaOCl}$ ) dalam sampel yang cukup keruh terhadap kestabilan nilai amonia, maka dilakukan percobaan untuk mengetahui sejauh mana pengaruh penambahan sodium hipoklorit dalam analisa amonia dalam air secara fenat sehingga dapat dijadikan dasar batasan penggunaan sodium hipoklorit tersebut.

\section{BAHAN DAN METODE}

\section{Bahan dan Peralatan}

Bahan yang digunakan dalam penelitian ini adalah fenol $\left(\mathrm{C}_{6} \mathrm{H}_{5} \mathrm{OH}\right)$, amonium klorida, $\left(\mathrm{NH}_{4} \mathrm{Cl}\right)$, sodium hidroksida $(\mathrm{NaOH})$, sodium hipoklorit $(\mathrm{NaOCl})$, asam sulfat $\left(\mathrm{H}_{2} \mathrm{SO}_{4}\right)$, aquadest bebas amonia, kertas lakmus dan kertas saring lembaran.

Peralatan terdiri dari pipet tetes, tabung reaksi, pipet ukur $10 \mathrm{~mL}$, pipet volum 5 $\mathrm{mL}, 10 \mathrm{~mL}$ dan $25 \mathrm{~mL}$, erlenmenyer 125
$\mathrm{mL}$, botol sampler, kotak pendingin (ice box), timbangan analitik, spektrofotometer UV-Vis, dan juga masker dan sarung tangan

\section{Metode Penelitian}

Penelitian diawali dengan persiapan sampel yang diformulasi dengan tingkat kekeruhan tinggi serta kadar amonia dalam kisaran nilai yang mudah dideteksi oleh alat. Selanjutnya diuji tingkat kekeruhan sesuai SNI 06 6989.25-2005 Air dan Air LimbahBagian 25: Cara Uji Kekeruhan dengan Nephelometer, dan kadar amonia sesuai SNI 06-6989.30-2005 Air dan Air Limbah-Bagian 30: Cara uji kadar Amonia dengan Spektrofotometer secara Fenat.

Sampel yang telah diketahui tingkat kekeruhan dan kadar amonia kemudian diuji lanjut dengan penambahan sodium hipoklorit ( $\mathrm{NaOCl}$ ) berbagai konsentrasi dalam masingmasing $100 \mathrm{~mL}$ larutan alkalin sitrat sebagai larutan pengoksidasi mengikuti tahapan uji pada standar uji SNI 066989.30-2005 sebagai berikut :

a. Pembuatan Zat Pereaksi

Pembuatan larutan pereakasi mengikuti tahapan uji kadar amonia sesuai SNI 06-6989.302005 Air dan Air Limbah-Bagian 30. Namun untuk pembuatan larutan pengoksidasi dengan cara mencampurkan $100 \mathrm{~mL}$ larutan alkalin sitrat (volume konstan) dengan $25,30,35,40,45,50,55$, $60 \mathrm{~mL}$ sodium hipoklorit ( $\mathrm{NaOCL}$ ) $5 \%$.

b. Tahapan Percobaan

1. Pembuatan larutan standard mengikuti tahapan uji kadar amonia sesuai SNI 06 6989.30-2005 Air dan Air Limbah-Bagian 30.

2. Pembuatan larutan kerja ammonia

Pembuatan larutan kerja amonia mengikuti tahapan uji kadar amonia sesuai SNI 06-6989.302005 Air dan Air Limbah-Bagian 30 . 
3. Pembuatan kurva kalibrasi

Pembuatan kurva kalibrasi mengikuti tahapan uji kadar amonia sesuai SNI 06-6989.302005 Air dan Air LimbahBagian 30.

c. Pengujian

1 Tahapan Pengujian Awal (Tetap)

a. Pipet $25 \mathrm{~mL}$ contoh uji masukkan ke dalam Erlenmeyer $50 \mathrm{~mL}$

b. Tambahkan $1 \mathrm{~mL}$ larutan fenol dan dihomogenkan

c. Tambahkan $1 \mathrm{~mL}$ natrium nitroprusid dihomogenkan

2 Tahapan Perlakuan (variabel bebas)

a. Tambahkan masing-masing $2.5 \mathrm{~mL}$ larutan pengoksidasi mengguna kan larutan pengoksidasi yang telah dibuat sebagaimana pada point (pembuatan zat pereaksi), ke dalam masingmasing sampel yang akan diujikan.

b. Tutup erlenmeyer tersebut dengan plastik atau paraffin film

c. Biarkan selama 1 jam untuk pembentukan warna

d. Masukkan ke dalam kuvet pada alat spektrofotometer. baca dan catat serapannya pada panjang gelombang $640 \mathrm{~nm}$

\section{Perhitungan}

Kadar amonia $(m g N / L)=C X$ fp

Dengan pengertian :

$\mathrm{C}$ adalah kadar yang didapat dari hasil pengukuran ( $\mathrm{mg} / \mathrm{L}$ ) $F p$ adalah factor pengencer an

\section{Pengujian}

Adapun parameter yang diujikan baik sampel sebelum maupun sesudah proses percobaan dengan penambahan sodium hipoklorit ( $\mathrm{NaOCl}$ ) dalam berbagai variasi konsentrasi adalah :

a. Kadar amonia dengan metode uji sesuai SNI 06-6989.30-2005, Cara
Uji Kadar Amonia dengan Spektrophotometer Secara Fenat, yang pada prinsipnya kandungan amonia sebagai $\mathrm{NH}_{3}-\mathrm{N}$ bereaksi dengan hipoklorit dan fenol dengan katalis natrium nitroprusida membentuk senyawa biru indofenol

b. Nilai $\mathrm{pH}$ yang diukur menggunakan metode uji sesuai SNI 06-6989.11-2004 yang pada prinsipnya pengukuran $\mathrm{pH}$ berdasarkan pengukuran aktifitas ion hidrogen secara potensiometri/ elektrometri dengan menggunakan $\mathrm{pH}$ meter

c. Nilai kekeruhan menggunakan metode uji sesuai SNI 06-6989.252005, Cara Uji Kekeruhan dengan Nefelometer, yang pada prinsipnya intensitas cahaya contoh uji yang diserap dan dibiaskan, dibandingkan terhadap intensitas cahaya suspensi baku.

\section{HASIL DAN PEMBAHASAN}

Faktor yang berpengaruh dalam analisa amonia adalah konsentrasi amonia dan faktor pengganggu (interference). Oleh karena itu faktor pengganggu dicoba dieleminir dengan penambahan sodium hipoklorit berlebih. Contoh uji yang digunakan dalam penelitian ini adalah contoh formulasi sintetik yang diperkaya dengan larutan amonia dengan tingkat kekeruhan tinggi yaitu 36,75 NTU serta pH 8,5. Sedangkan kadar amonia sampel sebesar $28,966 \mathrm{mg} / \mathrm{L}$ yang diuji menggunakan metode uji baku amonia (SNI 06-6989.30-2005) tentang cara uji kadar Amonia dengan Spektrofotometer secara Fenat. Selanjutnya kedalam sampel tersebut ditambahkan masingmasing $2,5 \mathrm{~mL}$ larutan pengoksidasi yang dibuat dari $25 \mathrm{~mL}, 30 \mathrm{~mL}, 35 \mathrm{~mL}$, $40 \mathrm{~mL}, 45 \mathrm{~mL}, 50 \mathrm{~mL}, 55 \mathrm{~mL}, 60 \mathrm{~mL}$ sodium hipoklorit dalam $100 \mathrm{~mL}$ larutan alkalin sitrat. Hasil uji rata-rata kadar amonia sampel sebagaimana tertera pada Tabel 1. 
Tabel 1. Kadar Amonia Sampel dengan Nilai Kekeruhan 36,75 NTU dan Warna Sampel $480,650 \mathrm{Pt} . \mathrm{Co}$

\begin{tabular}{|c|c|}
\hline $\begin{array}{c}\text { Volume NaOCL }(\mathrm{mL}) \text { dalam } 100 \mathrm{~mL} \text { larutan } \\
\text { alkalin sitrat }\end{array}$ & Kadar Amonia (mg/L) \\
\hline 25 & 28,9666 \\
\hline 30 & 29,2833 \\
\hline 35 & 29,3667 \\
\hline 40 & 29,2833 \\
\hline 45 & 29,7667 \\
\hline 50 & 28,5333 \\
\hline 55 & 27,9833 \\
\hline 60 & 27,6667 \\
\hline
\end{tabular}

Hasil uji kadar amonia dengan penambahan sodium hipoklorit $25 \mathrm{~mL}$ dalam $100 \mathrm{~mL}$ larutan alkalin sitrat sebagai larutan pengoksidasi yang ditetapkan dalam metode uji SNI 066989.30-2005, tentang cara uji kadar Amonia dengan Spektrofotometer secara fenat sekaligus sebagai kontrol dengan nilai rata-rata sebesar 28,9666 $\mathrm{mg} / \mathrm{L}$, mengalami kenaikan menjadi $29,2833 \mathrm{mg} / \mathrm{L}$ dengan penambahan sodium hipoklorit sebesar $30 \mathrm{~mL}$ dalam $100 \mathrm{~mL}$ larutan alkalin sitrat. Demikian pula dengan volume penambahan sodium hipoklorit $35 \mathrm{~mL}, 40 \mathrm{~mL}$ dan 45 $\mathrm{mL}$ dalam $100 \mathrm{~mL}$ larutan alkalin sitrat. Bahkan untuk kadar amonia tertinggi dari semua perlakuan dihasilkan dari penambahan sodium hipoklorit $45 \mathrm{~mL}$ dalam $100 \mathrm{~mL}$ larutan alkalin sitrat.

Sebaliknya dengan penam bahan $50 \mathrm{~mL}$ sodium hipoklorit dalam $100 \mathrm{~mL}$ larutan alkalin sitrat kadar amonia justru menurun menjadi $28,5333 \mathrm{mg} / \mathrm{L}$, demikian pula terjadi penurunan kadar amonia dengan penambahan sodium hipoklorit dalam volume yang lebih besar yaitu $55 \mathrm{~mL}$ dan $60 \mathrm{~mL}$ sebagaimana ditunjukkan Gambar 1. Hal ini dapat disebabkan oleh penambahan sodium hipoklorit yang semakin banyak akan mempengaruhi nilai $\mathrm{pH}$ yang semakin basa sehingga kadar amonia menjadi lebih kecil karena adanya oksidasi amonia menjadi nitrit $\left(\mathrm{NO}_{2}\right)$. Sebagaimana dijelaskan oleh Parson et.al 1984 dan Korelaf 1976 dalam Hutagalung P.H., dkk 1997 bahwa dalam suasana basa amonia bereaksi dengan sodium hipoklorit membentuk senyawa monokloramin. Senyawa monokloramin yang terbentuk ekivalen dengan banyaknya amonia yang terdapat dalam contoh air.

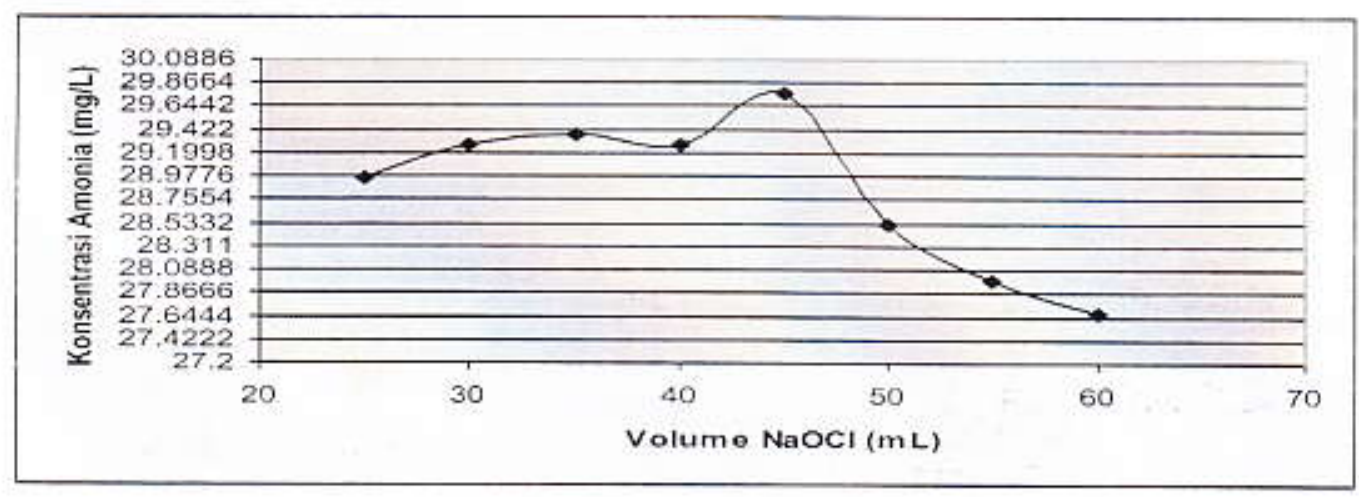

Gambar 1. Hubungan Volume $\mathrm{NaOCl}(\mathrm{mL})$ Terhadap Kadar Amonia (mg/L) Sampel Air.

Dengan adanya senyawa fenol dan hipoklorit berlebih menghasilkan senyawa indofenol yang berwarna biru (Parson et al. 1984; Korelaf 1976 dalam
Hutagulung P.H., dkk, 1997). Selanjutnya $\mathrm{pH}$ yang tinggi pada amonia justru teroksidasi menjadi nitrit $\left(\mathrm{NO}_{2}\right)$ dan amonia tidak terionisasi naik 
dengan naiknya $\mathrm{pH}$ (Anonim, 1992). Data hasil uji $\mathrm{pH}$ dengan penambahan sodium hipoklorit bervariasi dapat dilihat pada Tabel 3.

Untuk mengetahui sejauh mana penambahan sodium hipoklorit memberikan pengaruh terhadap nilai amonia dalam sampel uji maka dilakukan analisa sidik ragam. Hasil analisa dengan uji sidik ragam menunjukkan adanya pengaruh volume sodium hipoklorit yang ditambahkan dalam sampel uji terhadap kadar amonia baik pada taraf $5 \%$ maupun 1 $\%$ yang ditunjukkan nilai $\mathrm{F}$ hitung lebih besar dari nilai $F$ tabel (berbeda sangat nyata). Oleh karena itu dilanjutkan uji BNT pada taraf $5 \%$ dan $1 \%$ sebagaimana data Tabel 2.

Tabel 2. Hasil Uji BNT Pengaruh Sodium Hipoklorit terhadap Nilai Amonia

\begin{tabular}{|ccccc|}
\hline $\begin{array}{c}\text { Volume NaOCL (mL) } \\
\text { dalam } 100 \mathrm{~mL} \text { larutan } \\
\text { alkalin sitrat }\end{array}$ & $\mathrm{mg} / \mathrm{L}$ & Rata-rata & BNT $_{0,05}=0,48$ & BNT $_{0,01}=0,65$ \\
\hline 25 & $\mathrm{H} 0$ & 28,9666 & $\mathrm{bc}$ & $\mathrm{cd}$ \\
\hline 30 & $\mathrm{H} 1$ & 29,2833 & $\mathrm{c}$ & $\mathrm{d}$ \\
\hline 35 & $\mathrm{H} 2$ & 29,3667 & $\mathrm{c}$ & $\mathrm{d}$ \\
\hline 40 & $\mathrm{H} 3$ & 29,2833 & $\mathrm{c}$ & $\mathrm{d}$ \\
\hline 45 & $\mathrm{H} 4$ & 29,7667 & $\mathrm{~d}$ & $\mathrm{~b}$ \\
\hline 50 & $\mathrm{H} 5$ & 28,5333 & $\mathrm{~b}$ & $\mathrm{a}$ \\
\hline 55 & $\mathrm{H} 6$ & 27,9833 & $\mathrm{a}$ & $\mathrm{a}$ \\
\hline 60 & $\mathrm{H} 7$ & 27,6667 & $\mathrm{a}$ & \\
\hline
\end{tabular}

Keterangan

Angka-angka yang dikuti oleh huruf yang sama berarti berbeda tidak nyata $(5 \%)$ dan ( $1 \%)$.

Dari deret volume sodium hipoklorit yang ditambahkan berdasarkan uji BNT pada taraf $5 \%$ pengaruh sodium hipoklorit terhadap nilai amonia pada konsentrasi $25 \%$ berbeda tidak nyata dengan konsentrasi $30 \%, 35 \%$ dan $40 \%$, tetapi berbeda nyata dengan konsentrasi lainnya. Sedangkan untuk penambahan sodium hipoklorit dengan volume $45 \mathrm{~mL}$ berbeda nyata dengan konsentrasi lainnya. Selanjutnya pada taraf uji $1 \%$ pengaruh $\mathrm{NaOCl}$ terhadap nilai amonia pada konsentrasi $25 \%$ tidak berbeda nyata dengan konsentrasi $30 \%, 35 \%$ dan $40 \%$ tetapi berbeda nyata dengan konsentrasi lainnya. Dan untuk konsentrasi $45 \%$ berbeda sangat nyata dengan konsentrasi lainnya.

Dari hasil uji BNT berarti ada pengaruh penambahan sodium hipoklorit yang sangat menonjol yaitu penggunaan sodium hipoklorit $45 \mathrm{~mL}$ dibandingkan lainnya. Yang berarti pula untuk penambahan sodium hipoklorit 25 $\mathrm{mL}, 30 \mathrm{~mL}, 35 \mathrm{~mL}$, dan $40 \mathrm{~mL}$ dalam $100 \mathrm{~mL}$ larutan alkalin sitrat karena berbeda tidak nyata maka dapat dilakukan untuk sampel yang keruh namun khusus untuk sampel dengan konsentrasi amonia yang tinggi.

Sedangkan untuk konsentrasi amonia yang rendah walaupun tingkat kekeruhan dan warna sampel tinggi tidak disarankan adanya penambahan sodium hipoklorit lebih dari $25 \mathrm{~mL}$ dalam $100 \mathrm{~mL}$ larutan alkalin sitrat sesuai metode uji yang ditetapkan oleh SNI 066989.30-2005 tentang cara uji kadar Amonia dengan Spektrofotometer secara Fenat. Karena akan berpengaruh terhadap hasil uji amonia, dimana selisih pembacaan kadar amonia antara volume penambahan $25 \mathrm{~mL}, 30 \mathrm{~mL}, 35$ $\mathrm{mL}$ dan $40 \mathrm{~mL}$ dalam percobaan ini sangat kecil.

Sebagai data dukung untuk melihat efektifitas penurunan tingkat kekeruhan dengan penambahan sodium hipoklorit $(\mathrm{NaOCl})$ maka dilakukan analisa kekeruhan sampel dan warna masing-masing dari perlakuan sebagaimana pada Tabel 3. 
dengan $25,30,35,40,45,50,55,60$ $\mathrm{mL}$ sodium hipoklorit (NaOCL) $5 \%$.

b. Tahapan Percobaan

1. Pembuatan larutan standard mengikuti tahapan uji kadar amonia sesuai SNI 06 6989.30-2005 Air dan Air Limbah-Bagian 30.

2. Pembuatan larutan kerja ammonia

Pembuatan larutan keria amonia mengikuti tahapan uji kadar amonia sesuai SNI 066989.30-2005 Air dan Air Limbah-Bagian 30.

3. Pembuatan kurva kalibrasi

Pembuatan kurva kalibrasi mengikuti tahapan uji kadar amonia sesuai SNI 06-6989.302005 Air dan Air LimbahBagian 30 .

c. Pengujian

1 Tahapan Pengujian Awal (Tetap)

a. Pipet $25 \mathrm{~mL}$ contoh uji masukkan ke dalam Erlenmeyer $50 \mathrm{~mL}$

b. Tambahkan $1 \mathrm{~mL}$ larutan fenol dan dihomogenkan

c. Tambahkan $1 \mathrm{~mL}$ natrium nitroprusid dihomogenkan

2 Tahapan Perlakuan (variabel bebas)

a. Tambahkan masing-masing 2,5 $\mathrm{mL}$ larutan pengoksidasi mengguna kan larutan pengoksidasi yang telah dibuat sebagaimana pada point (pembuatan zat pereaksi), ke dalam masingmasing sampel yang akan diujikan.

b. Tutup erlenmeyer tersebut dengan plastik atau paraffin film

c. Biarkan selama 1 jam untuk pembentukan warna

d. Masukkan ke dalam kuvet pada alat spektrofotometer, baca dan catat serapannya pada panjang gelombang $640 \mathrm{~nm}$

3. Perhitungan

Kadar amonia $(\mathrm{mg} \mathrm{N} / \mathrm{L})=\mathrm{C}$

$X \mathrm{fp}$

Dengan pengertian:

$\mathrm{C}$ adalah kadar yang didapat dari hasil pengukuran $(\mathrm{mg} / \mathrm{L}$ )

$\mathrm{Fp}$ adalah factor pengencer an

\section{Pengujian}

Adapun parameter yang diujikan baik sampel sebelum maupun sesudah proses percobaan dengan penambahan sodium hipoklorit $(\mathrm{NaOCl})$ dalam berbagai variasi konsentrasi adalah :

a. Kadar amonia dengan metode uji sesuai SNI 06-6989.30-2005, Cara Uji Kadar Amonia dengan Spektrophotometer Secara Fenat, yang pada prinsipnya kandungan amonia sebagai $\mathrm{NH}_{3}-\mathrm{N}$ bereaksi dengan hipoklorit dan fenol dengan katalis natrium nitroprusida membentuk senyawa biru indofenol

b. Nilai pH yang diukur menggunakan metode uji sesuai SNI 06-6989.11-2004 yang pada prinsipnya pengukuran $\mathrm{pH}$ berdasarkan pengukuran aktifitas ion hidrogen secara potensiometri/ elektrometri dengan menggunakan pH meter

c. Nilai kekeruhan menggunakan metode uji sesuai SNI 06-6989.252005, Cara Uji Kekeruhan dengan Nefelometer, yang pada prinsipnya intensitas cahaya contoh uji yang diserap dan dibiaskan, dibandingkan terhadap intensitas cahaya suspensi baku.

\section{HASIL DAN PEMBAHASAN}

Faktor yang berpengaruh dalam analisa amonia adalah konsentrasi amonia dan faktor 
Tabel 3. Hasil Uji Nilai pH dan Tingkat Kekeruhan Sebelum dan Sesudah Penambahan Sodium Hipoklorit

\begin{tabular}{|ccc|}
\hline $\begin{array}{c}\text { Volume NaOCL }(\mathrm{mL} \text { ) dalam } \\
\text { alkalin sitrat }\end{array}$ & $\mathrm{pH} \mathbf{m L}$ larutan & Kekeruhan (NTU) \\
\hline Sebelum penambahan & 8,5 & 36,75 \\
\hline 25 & 9,7 & 15,37 \\
\hline 30 & 9,8 & 14,10 \\
\hline 35 & 9,8 & 13,43 \\
\hline 40 & 9,8 & 11,80 \\
\hline 45 & 9,8 & 11,60 \\
\hline 50 & 9,9 & 10,97 \\
\hline 55 & 9,9 & 10,60 \\
\hline 60 & 9,9 & 10,53 \\
\hline
\end{tabular}

Secara umum untuk tingkat kekeruhan sampel dengan penambahan sodium hipoklorit mengalami penurunan yang cukup besar. Untuk sampel yang digunakan dalam penelitian sebelum adanya penambahan sodium hipoklorit nilai kekeruhan sampel sebesar 36,75 NTU, dengan penambahan $25 \mathrm{~mL}$ sodium hipoklorit dapat turun menjadi 15,37 NTU atau turun sebesar $58,17 \%$, demikian pula untuk volume sodium hipoklorit yang lebih besar.

\section{KESIMPULAN DAN SARAN}

Penggunaan sodium hipoklorit $(\mathrm{NaOCl})$ untuk menurunkan kekeruhan dan warna dalam analisa air dan air limbah, menggunakan metode SNI 06 6989.30-2005, tentang cara uji kadar Amonia dengan Spektrofotometer secara Fenat berlebih berpengaruh terhadap nilai aktual amonia dalam air. Volume yang masih dapat digunakan adalah maksimum $40 \mathrm{~mL}$ sodium hipoklorit dalam $100 \mathrm{~mL}$ larutan alkalin sitrat.

\section{DAFTAR PUSTAKA}

Anonim 2009. Amonia $\left(\mathrm{NH}_{3}\right)$ http://maswira.wordpress.com, dikunjungi pada

tanggal 2 Januari 2009

Hanafiah Kemas Ali, 1993. Rancangan Percobaan. Teori dan Aplikasi. Edisi revisi. Fakultas Pertanian Universtitas Sriwijaya Palembang.

Hutagulung H.P., Setiapermana D., Riyono S. Hadi., 1997. Metode Analisa Air Laut, Sedimen dan Biota, Buku 2. Pusat Penelitian dan Pengembangan Oseanologi, LIPI.

SNI 06-6989.30-2005. Air dan Air Limbah-Bagian 30: Cara uji kadar Amonia dengan Spektrofotometer secara Fenat. Badan Standardisasi Nasional. Jakarta. Indonesia.

SNI 06-6989.25-2005 Air dan Air Limbah-Bagian 25: Cara Uji Kekeruhan dengan Nefelometer. Badan Standardi sasi Nasiona (BSN)I. Jakarta. Indonesia.

SNI 06-2413-1991 Air dan Air Limbah: Cara Uji Warna. Badan Standardisasi Nasional (BSN). Jakarta. Indonesia. 